\title{
Lessons from the Self-Organisation Concept for Geological and Ore Forming Processes
}

\section{SABINE DIETRICH}

\author{
Alumna TU Berlin
}

Presenting Author: sabine.dietrich@alumni.tu-berlin.de

\section{Lessons from the Self-Organisation Concept for Geological and Ore Forming Processes}

Geological systems and ore bodies in the earth's crust often display rhythmic patterns such as banded formations, layered and folded structures, diapirs or cockade ores that range in size from just a few millimetres to several kilometres.

For a long time, this topic has been examined from a thermochemical-mechanical perspective, seldom along with the numerical modelling of the processes. We proposed applying the concept of self-organisation to mineral deposits and geological processes in general. Recognising geological systems, mineral deposits and ore bodies as ordered structures implies to consider them as a system in which their components and properties are distributed in space and time, providing fundamental aspects of understanding them. Thus, the complexity in describing connections and feedback between contributing key processes can be reduced, leading to a better understanding and achievable numerical simulations.

The proof of concept was validated by examining a recent early diagenetic banded iron-manganese mud in an abandoned underground mine with precipitation that had accumulated over 40 years. Two years of in-situ testing revealed that the selforganising nature of the precipitated material was not only caused by fluctuations but also by interaction with redox, colloid, microbial, electrical and Ostwald-ripening processes. A genetic model for the banded mineralisation was developed and successfully verified by numerical simulation.

Moreover, gradients, such as concentration gradients, electric fields and the like, as well as temperature and pressure, enabled a coupling of the ongoing processes that is spatially and temporally far-reaching.

This leapfrog thinking could gain overall meaning if the previous ideas on the genesis of ordered structures in sedimentary, hydrothermal, magmatic and metamorphic ore bodies and geological systems, and thus the emergence of mineral resources in the earth's crust as part of the complex earth system, were re-examined in one case or another. In other words, it would permit the discovery of information about geological and ore forming processes, hidden by time, environmental conditions or by location, and bring them to light. 